\title{
IL-17 expression is correlated with hepatitis B- related liver diseases and fibrosis
}

\author{
LIYUN WANG $^{1 *}$, SHIJUN CHEN ${ }^{1,2^{*}}$ and $\mathrm{KESHU} \mathrm{XU}^{1}$ \\ ${ }^{1}$ Division of Gastroenterology, Union Hospital, Tongji Medical College, Huazhong University \\ of Science and Technology, Jiefang Avenue 1277, Wuhan 430022; ${ }^{2}$ Hospital for \\ Infectious Diseases, Jinan 250021, Shandong Province, P.R. China
}

Received September 24, 2010; Accepted November 26, 2010

DOI: $10.3892 / \mathrm{ijmm} .2011 .594$

\begin{abstract}
IL-17-producing T cells (Th17) have been found to play important roles in several liver diseases, but few studies have evaluated the function of such cells in hepatitis B (HBV)-related diseases, especially in hepatic fibrosis. In this study, we examined the expression of IL-17 in patients with different chronic HBV-related diseases, and assessed the association between IL-17 expression and the degree of fibrosis. The method of immunohistochemistry was used to evaluate the localization of intrahepatic IL-17. We demonstrated significantly increased expression of IL-17 in HBV-related chronic liver diseases, especially in liver fibrosis, and that the level of IL-17 is strongly correlated with the degree of fibrosis. Furthermore, we found that intrahepatic IL-17 was mainly localized in the fibrosis region. Our data reveal important roles of IL-17 and IL-17-producing cells in the progression of HBV related chronic liver diseases, especially in the formation of liver fibrosis.
\end{abstract}

\section{Introduction}

Hepatitis B virus (HBV) infection is one of the most important infectious diseases in the digestive system, especially in China, where the infection rate reaches over 58.6\%. There are more than 350 million people around the world suffering from persistent $\mathrm{HBV}$ infection. Of these, 10-20\% will develop liver cirrhosis and in $1-5 \%$ the disease will progress to hepatocellular carcinomas. The study of the pathogenesis of chronic

Correspondence to: Dr Keshu Xu, Division of Gastroenterology, Union Hospital, Tongji Medical College, Huazhong University of Science and Technology, Jiefang Avenue 1277, Wuhan 430022, P.R. China

E-mail:xuzou@medmail.com.cn

${ }^{*}$ Contributed equally

Abbreviations: HA, hyaluronic acid; IV-C, type IV collagen; PCIII, procollagen type III; LN, laminin

Key words: IL-17, hepatitis B, liver fibrosis, T cell, liver cirrhosis hepatitis B and the early blocking of the disease progression is important in order to reduce the incidence of liver cirrhosis and hepatocellular carcinoma.

Traditionally, the imbalance of Th1/Th2 cells was considered the conventional mechanism that decided the clearance and the development of HBV infection. Recent studies have shown that, in reference to the different cytokines of the local micro-environment, aside from $\mathrm{Th} 1 \mathrm{CD}^{+} \mathrm{T}$ cells producing interferon $\gamma(\mathrm{IFN}-\gamma)$ and Th2 CD4 ${ }^{+} \mathrm{T}$ cells producing IL-4, IL-5, and IL-13, Th17 cells comprise a newly discovered proinflammatory T-cell subset producing IL-17. IL-17 can mobilize, recruit, and activate neutrophils, leading to massive tissue inlammation and can promote the progression of autoimmune diseases (1-3). IL-17 was recently found to be extensively involved in the pathogenesis of chronic liver disease and antiviral immunity (4). In alcoholic liver disease, IL-17 is also responsible for neutrophil recruitment into the liver (5). In addition, there is research indicating a role of Th17 cells in liver damage of chronic hepatitis B (CHB) patients (6). These studies provide evidence linking the IL-17 pathway with immune-mediated liver injury. However, the relationship between IL-17 and fibrosis in chronic HBV diseases remains unclear.

Liver fibrosis is an important link in the development of chronic viral hepatitis into cirrhosis. Recent studies have found that both the natural and the acquired immunity systems play important roles in regulating liver fibrosis and tissue repair and recovery, which are vital for the maintenance of tissue homeostasis. Macrophages regulate the induction and resolution of liver fibrosis. Migration and positioning of $\mathrm{T}$ cells is determined by patterns of cytokine and chemokine secretion within the stroma (7). However, the participation of IL-17 in chronic inflammation caused by HBV and its role in liver fibrosis has not been reported.

The present study was undertaken to determine IL-17 expression in the serum, peripheral blood mononuclear cells (PBMCs) and in liver tissues of patients with chronic HBV-related diseases, such as chronic HBV hepatitis, chronic severe hepatitis B, CHB, liver cirrhosis (LC), and hepatocellular carcinoma; to associate liver fibrosis stages with levels of IL-17 expression; to explore the significance of IL-17 in HBV-related liver disease; and to suggest the possible role of Il-17 in the immune mechanism of hepatitis and liver fibrosis. 
Table I. Clinical characteristics of the populations enrolled in the study.

\begin{tabular}{lcccccc}
\hline Group & CHB & Cirrhosis & HCC & $\begin{array}{c}\text { Chronic severe } \\
\text { hepatitis }\end{array}$ & ASC & Healthy controls \\
\hline Case & 55 & 42 & 34 & 30 & 30 & 20 \\
Sex(M/F) & $32 / 23$ & $29 / 13$ & $24 / 10$ & $22 / 8$ & $18 / 12$ & $14 / 6$ \\
Age, years (range) & $31(17-45)$ & $51(40-63)$ & $54(47-61)$ & $47(40-53)$ & $31(17-46)$ & $34(22-46)$ \\
HBsAg(+) & 55 & 42 & 33 & 30 & 30 & 0 \\
Child-Pugh (A/B/C) & - & $15 / 15 / 12$ & - & - & - & - \\
\hline
\end{tabular}

\section{Materials and methods}

Patients. Blood samples were collected from 55 patients with CHB, 42 patients with post-HBV hepatitis cirrhosis, 34 patients with hepatic carcinoma, 30 patients with chronic severe HBV hepatitis, 30 surface antigen carrier (ASC) patients, and 20 age- and sex-matched healthy individuals were enrolled as healthy controls. All the patients were adults, with positive $\mathrm{HBsAg}$, and all cases of cirrhosis were in the active stage (Table I). The diagnosis was performed in line with international diagnostic criteria. Individuals with concurrent $\mathrm{HCV}$, hepatitis $\mathrm{G}$ virus, and human immunodeficiency virus (HIV)-1 infection, autoimmune liver diseases or who met clinical or biological criteria of bacterial or fungal infection were excluded from the study (8).

Liver samples were biopsy samples obtained from 30 patients of ASC, 55 CHB patients, and 55 LC patients.

Enzyme-linked immunosorbent assay (ELISA). Peripheral blood samples of patients and normal controls were collected and placed in tubes free of pyrogen and endotoxin. After centrifugation at a speed of $1000 \mathrm{x} \mathrm{g}$ for $15 \mathrm{~min}$, serum samples were harvested and stored at $-70^{\circ} \mathrm{C}$ until use. IL-17, anti-HBVM and indicators of liver fibrosis including HA, type IV collagen (IV-C), procollagen type III (PCIII) and LN were determined in the serums using commercially available ELISAs (R\&D Systems Minneapolis, MN, USA), according to the manufacturer's instructions. The sensitivity of the assays was $<15 \mathrm{pg} / \mathrm{ml}$ for IL-17 testing.

RNA extraction and reverse-transcription polymerase chain reaction (RT-PCR). The RNA expression of IL-17 in PBMCs was detected with the method of RT-PCR. The sequences of the primers for IL-17 were 5'-AGAGATATCCCTCTG GATC-3' (forward) and 5'-TACCCCAAAGTTATCTCAGG-3' (reverse), while the sequences of the primers for $\beta$-actin were 5'-CATGTACGTTGCTATCCAGGC-3' (forward) and 5'-CTCCTTAATGTCACGCACGAT-3' (reverse), both synthesized by the BoYa Biological Reagents Company (Shanghai, China).

Using EDTA as an anticoagulant, PBMCs were separated by density gradient centrifugation with a lymphocyte separation medium. PCR amplifications were performed using an Advantage cDNA PCR kit (Promega) with a $20 \mu \mathrm{l}$ final reaction mixture consisting of $2 \mu \mathrm{l}$ cDNA samples, $0.3 \mu \mathrm{l}$ of the primers for each target cDNA, $9.9 \mu \mathrm{l}$ of $\mathrm{ddH}_{2} \mathrm{O}, 12.5 \mu \mathrm{l}$ Advantage cDNA polymerase mix and $1 \mu \mathrm{l}$ cDNA PCR reaction buffer. The PCR conditions included an initial denaturation step at $94^{\circ} \mathrm{C}$ for $5 \mathrm{~min}$ followed by 35 cycles of $94^{\circ} \mathrm{C}$ for $40 \mathrm{sec}, 48^{\circ} \mathrm{C}$ for $40 \mathrm{sec}$ and $72^{\circ} \mathrm{C}$ for $40 \mathrm{sec}$, and a final extension step of $7 \mathrm{~min}$ at $72^{\circ} \mathrm{C}$.

Immunohistochemical staining. Paraffin-embedded, formalin-fixed liver tissue sections $(4 \mu \mathrm{m})$ were incubated with anti-IL-17 (1:100) (H-132, sc7927, Santa Cruz Biotechnology, lot\#2407) overnight at $4^{\circ} \mathrm{C}$ after blocking endogenous peroxidase activity with $0.3 \% \mathrm{H}_{2} \mathrm{O}_{2}$. Sections were then incubated with a goat-anti-rabbit secondary antibody for $30 \mathrm{~min}$. After washing off the free antibodies with PBS, autoradiography was performed with DAB (3,3'-diaminobenzidine) followed by counterstaining with hematoxylin. Negative blank controls were prepared during the staining, in which the first antibody was omitted and replaced with PBS. Scores were given according to the level and the range of the color as follows: 0 points, no positive color; 1 point, $<26 \%$ positive staining; 2 points, $26-50 \%$; 3 points, $51-75 \%$; and 4 points, $>75 \%$ positive staining.

Detection of biochemical indicators in the serum. ALT, AST, TBil, albumin (A), globulin (G) and other indicators of liver function were detected with an automatic biochemical analyzer (Ci8200, Abbott Company).

Detection of serum HBV-DNA. Accurate quantification of HBV-DNA was performed by real-time PCR. Real-time quantitative PCR was run on a fluorescent PCR detector (PE GeneAmp 7300) according to the manufacturer's recommendations. The real-time quantitative PCR reaction contained $25 \mu 12$ X SYBR Premix Ex Taq ${ }^{\mathrm{TM}}$ (Takara), $2 \mu$ l primer mix, $1 \mu \mathrm{l}$ 50X ROX ${ }^{\mathrm{TM}}$ Reference Dye II, $4 \mu \mathrm{l} \mathrm{cDNA}$, and $18 \mu \mathrm{l}$ deionized water to make a total volume of $50 \mu \mathrm{l}$. After setting the amplification conditions, the experiments were repeated twice. The primers for IL-17 were 5'-AGAGATATCCCTC TGTGATC-3' and 5'-TACCCCAAAGTTATCTCAGG-3'; the primers for $\beta$-actin were 5'-CATGTACGTTGCTATCCA GGC-3' and 5'-CTCCTTAATGTCACGCACGAT-3'.

Data presentation and statistical analysis. The SPSS 12.0 statistical software was used for the analysis, and the data were displayed as mean \pm SME. The Kruskal-Wallis and Mann-Whitney tests and the Pearson correlation analysis were used to analyze all the data. A P-value of $<0.05$ was considered to be significant. When pairwise comparisons between groups with the Mann-Whitney test were analyzed, 
Table II. Serum levels and the relative ratios of cytokines in the different groups ( $\mathrm{pg} / \mathrm{ml})$.

\begin{tabular}{lllcccl}
\hline Group & N & \multicolumn{1}{c}{ IL-17 } & IFN- $\gamma$ & IL-4 & IFN- $\gamma / I L-4$ & IFN- $\gamma /$ IL-17 \\
\hline Control & 22 & $28.2 \pm 7.88$ & $78.75 \pm 12.76$ & $30.90 \pm 4.44$ & $2.60 \pm 0.60$ & $2.66 \pm 0.70$ \\
CHB & 55 & $38.8 \pm 11.38^{\mathrm{a}, \mathrm{c}}$ & $44.43 \pm 32.48^{\mathrm{a}}$ & $40.65 \pm 9.76^{\mathrm{a}}$ & $1.08 \pm 0.66^{\mathrm{a}}$ & $1.13 \pm 0.85^{\mathrm{a}}$ \\
Severe hepatitis & 22 & $42.3 \pm 3.89^{\mathrm{b}, \mathrm{c}}$ & $150.65 \pm 12.76^{\mathrm{a}, \mathrm{d}}$ & $32.70 \pm 8.94$ & $4.81 \pm 0.87^{\mathrm{a}, \mathrm{e}}$ & $3.68 \pm 0.42^{\mathrm{a}, \mathrm{e}}$ \\
Hepatic cirrhosis & 32 & $63.8 \pm 20.82^{\mathrm{b}}$ & $77.49 \pm 20.96^{\mathrm{e}}$ & $32.83 \pm 6.87$ & $2.38 \pm 0.49$ & $1.69 \pm 0.92^{\mathrm{a}}$
\end{tabular}

Compared to normal controls, ${ }^{\mathrm{a}}<0.05$, ${ }^{\mathrm{b}} \mathrm{P}<0.01$; compared to hepatic cirrhosis, ${ }^{\mathrm{C}} \mathrm{P}<0.01$; compared to $\mathrm{CHB},{ }^{\mathrm{d}} \mathrm{P}<0.05$; compared to other groups, eP<0.01.

the corrected $\alpha$-value was the applicator and a $\mathrm{P}<0.05$ was considered to be statistically significant. In order to compare between each two data, t-tests of independent samples were performed. Pearson correlation analysis was used to analyze the correlation between the variables, and to judge the correlation between the expression of IL-17 and the pathologic degree, stage and serum liver fibrosis markers.

\section{Results}

Serum expressions of IL-17 and other cytokines in patients of different groups. Compared with the normal control group, the serum concentrations of IL-17 significantly increased in patients with $\mathrm{CHB}$, severe hepatitis $\mathrm{B}$, and hepatic cirrhosis (all P-values were <0.05). Meanwhile, the concentration of
IL-17 in patients of the hepatic cirrhosis group was significantly higher than that in patients of the other groups. P-values were $<0.01$ compared to both the $\mathrm{CHB}$ and the severe hepatitis B groups, but there was no significant difference in the expression of IL-17 between the CHB and severe hepatitis $\mathrm{B}$ $(\mathrm{P}=0.260)$ groups (Table II).

Compared with the control group, IFN- $\gamma$ was found to be significantly decreased in CHB group (P-values $<0.01$ ), but it showed an opposite trend in patients with severe hepatitis, in which IFN- $\gamma$ was significantly elevated compared with the control group (P-values <0.01). Expression of IL-4 in the $\mathrm{CHB}$ group was significantly higher than in the control group $(\mathrm{P}<0.05)$, while no significant differences were found in the severe hepatitis and liver cirrhosis groups compared to the control group.
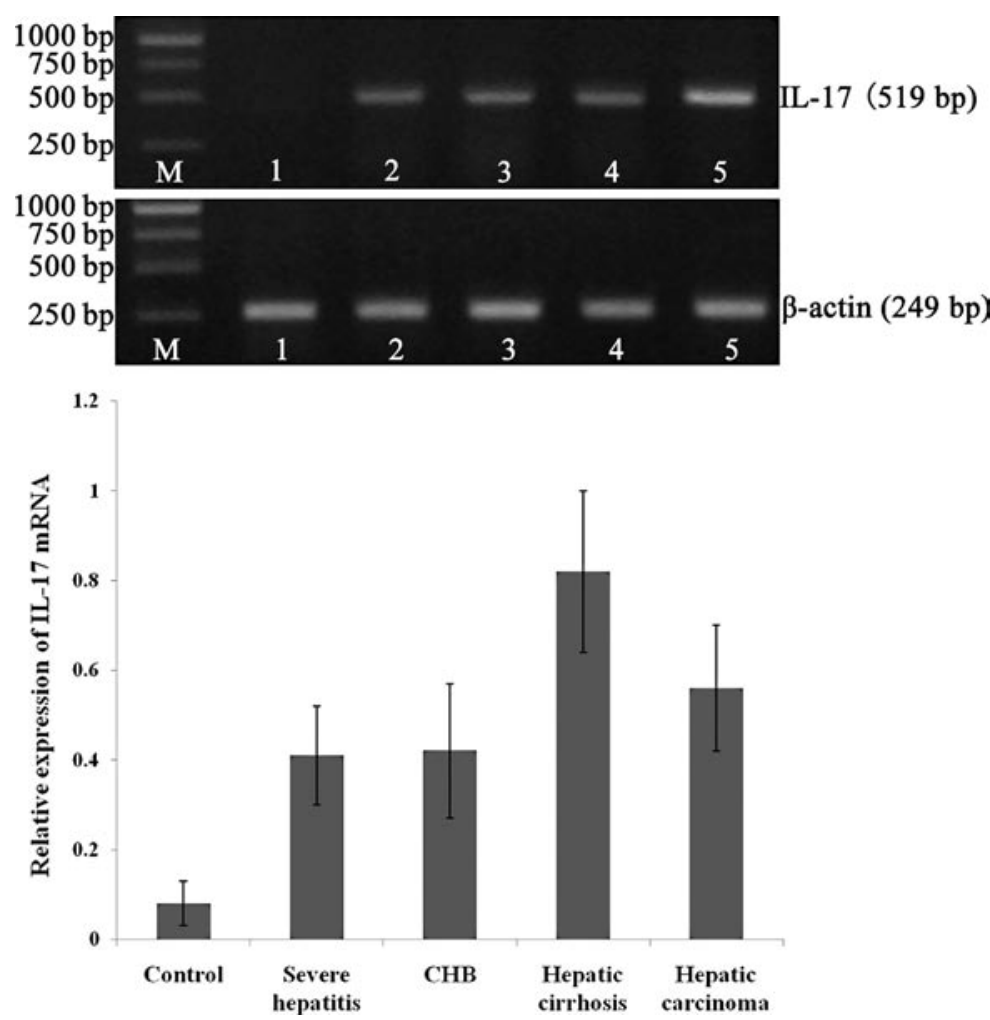

Figure 1. mRNA expressions of IL-17 in PBMCs of patients with different diseases. Lane M, marker; 1, normal control; 2, CHB; 3, severe hepatitis; 4, hepatitis carcinoma; 5, liver cirrhosis. The expression of IL-17 in PBMCs of the four groups of patients were significantly increased compared with the control group $(\mathrm{P}<0.01)$. Furthermore, the most significant increase of IL-17 expression was found in patients with liver cirrhosis, compared to the other three groups of patients (all P-values <0.01). 

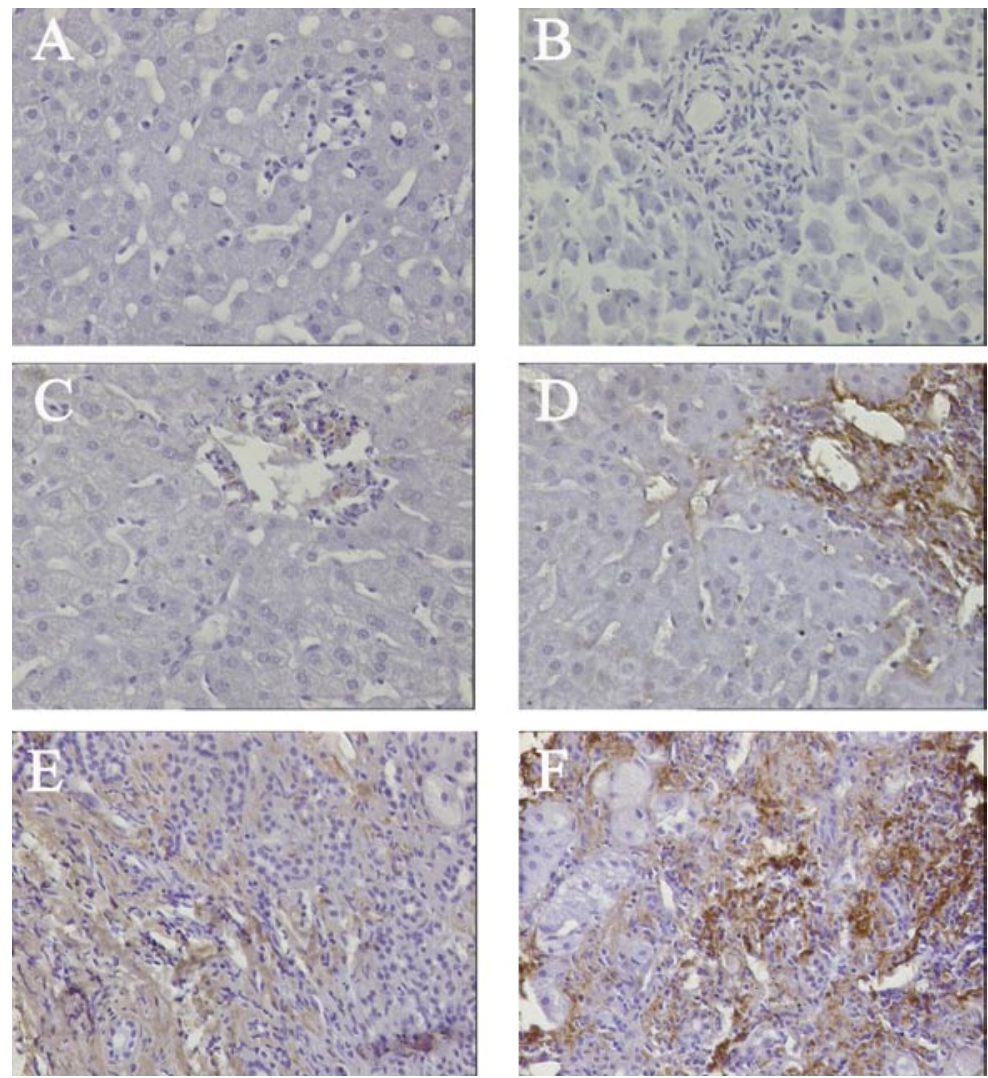

Figure 2. Different staining intensity of IL-17 in patients with different diseases (x400). Expressions of IL-17 increased in order in patients with (C) surface antigen carrier (ASC); (D) CHB; (E) inactive liver cirrhosis; (F) active cirrhosis. The strongest expression of IL-17 was found in the patients with active liver cirrhosis. (A) and (B) blank control.
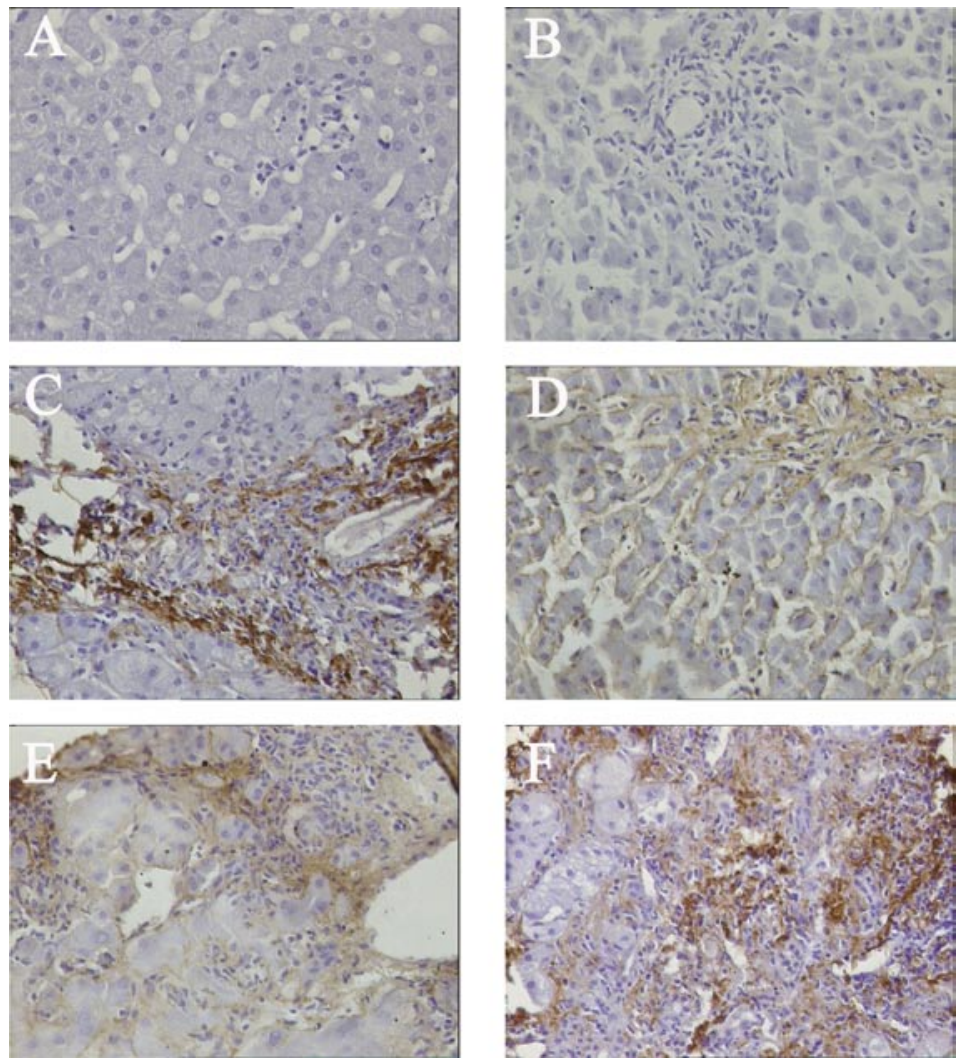

Figure 3. Localization of IL-17 (x400). Strong positive staining was observed in the following regions: (C) fibroblasts of the fibrosis areas; (D) sinusoidal endothelial cells; (E) lymphocytes of fibrosis areas and (F) periportal and fibrosis areas. Positive staining was mainly detected in the cytoplasm, cell membrane and interstitium; (A) and (B) blank control. 
Table III. Score of intrahepatic IL-17 expression and markers of fibrosis in serum of patients with different diseases (pg/ml).

\begin{tabular}{lcccccc}
\hline Group & $\mathrm{N}$ & IV-C & LN & HA & PCIII & IL-17 score \\
\hline ASC & 30 & $108.25 \pm 20.23$ & $92.67 \pm 10.35$ & $92.46 \pm 17.88$ & $8.77 \pm 1.46$ & $0.87 \pm 0.63$ \\
CHB & 55 & $256.54 \pm 10.83^{\mathrm{a}}$ & $104.21 \pm 12.66$ & $143.53 \pm 16.98^{\mathrm{a}}$ & $14.76 \pm 4.58^{\mathrm{b}}$ & $2.58 \pm 0.19^{\mathrm{b}}$ \\
Cirrhosis & 42 & $398.67 \pm 11.54^{\mathrm{b}}$ & $361.33 \pm 10.89^{\mathrm{b}}$ & $344.23 \pm 15.64^{\mathrm{b}}$ & $24.60 \pm 6.18^{\mathrm{b}}$ & $3.75 \pm 0.44^{\mathrm{b}}$ \\
\hline
\end{tabular}

${ }^{\mathrm{a}} \mathrm{P}<0.05,{ }^{\mathrm{b}} \mathrm{P}<0.01$ compared to ASC.

Table IV. Score of intrahepatic IL-17 expression and markers of fibrosis in serum of patients with different grades of fibrosis $(\mathrm{pg} / \mathrm{ml})$.

\begin{tabular}{|c|c|c|c|c|c|c|}
\hline Stage & $\mathrm{N}$ & IV-C & $\mathrm{LN}$ & HA & PCIII & IL-17 score \\
\hline So & 12 & $101.38 \pm 17.23$ & $89.38 \pm 14.94$ & $85.75 \pm 9.98$ & $8.38 \pm 1.41$ & $0.75 \pm 0.71$ \\
\hline $\mathrm{S} 1$ & 32 & $131.50 \pm 40.71^{\mathrm{a}}$ & $103.00 \pm 18.92$ & $108.36 \pm 31.69$ & $9.22 \pm 1.44$ & $1.36 \pm 0.76^{\mathrm{a}}$ \\
\hline $\mathrm{S} 2$ & 48 & $275.14 \pm 90.51^{b}$ & $237.58 \pm 80.16^{b}$ & $239.42 \pm 70.04^{b}$ & $15.67 \pm 4.28^{\mathrm{b}}$ & $2.50 \pm 0.83^{a}$ \\
\hline S3 & 27 & $348.06 \pm 72.31^{b}$ & $284.88 \pm 86.09$ & $305.88 \pm 56.49^{b}$ & $17.65 \pm 3.33$ & $3.12 \pm 0.69^{a}$ \\
\hline $\mathrm{S} 4$ & 42 & $405.30 \pm 62.28^{\mathrm{a}}$ & $380.05 \pm 58.28^{b}$ & $361.25 \pm 75.29^{\mathrm{a}}$ & $24.60 \pm 6.18^{\mathrm{b}}$ & $3.75 \pm 0.44^{b}$ \\
\hline
\end{tabular}

${ }^{\mathrm{a}} \mathrm{P}<0.05,{ }^{\mathrm{b}} \mathrm{P}<0.01$ compared to $\mathrm{S} 0$.

mRNA expressions of IL-17 in PBMCs of patients of different groups. IL-17 mRNA expression in PBMCs of patients of the four groups was enhanced (all P-values $<0.01$ ), especially in patients of the hepatic cirrhosis group, among which mRNA expressions of IL-17 were significantly higher than in the other three groups (all P-values <0.01). Meanwhile, mRNA expressions of IL-17 in hepatic cancer were found to be higher than in the CHB and severe hepatitis groups (all P-values <0.01). No obvious difference in IL-17 mRNA expression was found between patients of the $\mathrm{CHB}$ and the severe hepatitis groups $(\mathrm{P}=0.857)$ (Fig. 1).

Histological expression of $I L-17$ in the liver of patients of different groups. There was no positive staining in blank controls (Fig. 2A and B), but with the progression from ASC, to chronic hepatitis $\mathrm{B}$, to post-HBV hepatitis cirrhosis, the expression of IL-17 increased in order (Fig. 2).

IL-17 was mainly localized in periportal areas, in lymphocytes of the fibrosis area, in fibroblasts and in sinusoidal endothelial cells (Fig. 3). Positive staining was detected in the cytoplasm, cell membrane and interstitium.
Relationship between liver expression of IL-17 and the level of liver fibrotic markers. As the liver diseases progressed, the degree of hepatic inflammation and liver fibrosis got higher, which were manifested by gradual increases in the expression of four indicators of liver fibrosis, namely, IV-C, LN, HA, and PCIII. In our study, expressions of these fibrotic markers of patients with post-hepatitis cirrhosis $(398.67 \pm 11.54 ; 361.33 \pm 10.89 ; 344.23 \pm 15.64 ; 24.60 \pm 6.18)$ were significantly higher than those of the patients with $\mathrm{CHB}$ $(256.54 \pm 10.83 ; 104.21 \pm 12.66 ; 143.53 \pm 16.98 ; 14.76 \pm 4.58)$. Meanwhile, the expressions of IV-C, HA, and PCIII of the CHB group were also significantly higher than those of the HBV ASC $(108.25 \pm 20.23 ; 92.46 \pm 17.88 ; 8.77 \pm 1.46)(\mathrm{P}<0.05)$ (Tables III).

When classified by the diseases, consistent with the alterations of the fibrotic markers in the different groups of patients, the intrahepatic expression of IL-17 in patients of the posthepatitis cirrhosis group $(3.75 \pm 0.44)$ was significantly higher than that of the patients with $\mathrm{CHB}(2.58 \pm 0.19)(\mathrm{P}<0.01)$, and the latter was also significantly higher than that of the HBV ASC $(0.87 \pm 0.63)(\mathrm{P}<0.01)$ (Table III).

Table V. Score of intrahepatic IL-17 expression in different hepatic inflammation stages (pg/ml).

\begin{tabular}{lllcccc}
\hline Stage & N & IV-C & LN & HA & PCIII & IL-17 score \\
\hline G0-1 & 44 & $122.45 \pm 68.37$ & $106.90 \pm 61.92$ & $99.03 \pm 48.38$ & $9.28 \pm 2.36$ & $0.97 \pm 0.77$ \\
G2 & 53 & $224.74 \pm 92.39^{\mathrm{b}}$ & $175.18 \pm 83.27^{\mathrm{b}}$ & $189.67 \pm 78.75^{\mathrm{b}}$ & $13.38 \pm 5.62^{\mathrm{b}}$ & $2.28 \pm 0.79^{\mathrm{b}}$ \\
G3 & 44 & $348.06 \pm 72.31^{\mathrm{b}}$ & $284.88 \pm 86.09^{\mathrm{b}}$ & $320.30 \pm 59.28^{\mathrm{b}}$ & $19.50 \pm 4.87$ & $3.30 \pm 0.75^{\mathrm{b}}$ \\
G4 & 20 & $418.14 \pm 56.43$ & $396.00 \pm 65.32^{\mathrm{a}}$ & $411.43 \pm 65.00^{\mathrm{b}}$ & $27.43 \pm 4.96^{\mathrm{b}}$ & $3.86 \pm 0.37^{\mathrm{a}}$ \\
\hline
\end{tabular}

${ }^{\mathrm{a}} \mathrm{P}<0.05,{ }^{\mathrm{b}} \mathrm{P}<0.01$ compared to $\mathrm{G} 0-1$. 
Table VI. Correlation.

\begin{tabular}{|c|c|c|c|c|c|c|c|c|c|c|c|}
\hline & & IL-17 & ALT & AST & HA & $\mathrm{LN}$ & $\mathrm{C} 3$ & $\mathrm{C} 4$ & G & $\mathrm{S}$ & LGHBV \\
\hline \multirow[t]{3}{*}{ IL-17 } & Pearson correlation & 1 & .225 & .367 & .832 & .818 & .767 & .849 & .783 & .812 & -.081 \\
\hline & 2-tailed significance & . & .021 & .000 & .000 & .000 & .000 & .000 & .000 & .000 & .411 \\
\hline & $\mathrm{N}$ & 105 & 105 & 105 & 105 & 105 & 105 & 105 & 105 & 105 & 105 \\
\hline \multirow[t]{3}{*}{ ALT } & Pearson correlation & .225 & 1 & .804 & .297 & .282 & .246 & .297 & .253 & .157 & .076 \\
\hline & 2-tailed significance & .021 & . & .000 & .002 & .004 & .012 & .002 & .009 & .111 & .441 \\
\hline & $\mathrm{N}$ & 105 & 105 & 105 & 105 & 105 & 105 & 105 & 105 & 105 & 105 \\
\hline \multirow[t]{3}{*}{$\mathrm{AST}$} & Pearson correlation & .367 & .804 & 1 & .444 & .480 & .436 & .449 & .479 & .357 & .028 \\
\hline & 2-tailed significance & .000 & .000 & . & .000 & .000 & .000 & .000 & .000 & .000 & .773 \\
\hline & $\mathrm{N}$ & 105 & 105 & 105 & 105 & 105 & 105 & 105 & 105 & 105 & 105 \\
\hline \multirow[t]{3}{*}{$\mathrm{HA}$} & Pearson correlation & .832 & .297 & .444 & 1 & .924 & .887 & .938 & .835 & .861 & -.064 \\
\hline & 2-tailed significance & .000 & .002 & .000 & . & .000 & .000 & .000 & .000 & .000 & .517 \\
\hline & $\mathrm{N}$ & 105 & 105 & 105 & 105 & 105 & 105 & 105 & 105 & 105 & 105 \\
\hline \multirow[t]{3}{*}{$\mathrm{LN}$} & Pearson correlation & .818 & .282 & .480 & .924 & 1 & .878 & .936 & .789 & .862 & -.052 \\
\hline & 2-tailed significance & .000 & .004 & .000 & .000 & . & .000 & .000 & .000 & .000 & .596 \\
\hline & $\mathrm{N}$ & 105 & 105 & 105 & 105 & 105 & 105 & 105 & 105 & 105 & 105 \\
\hline \multirow[t]{3}{*}{$\mathrm{C} 3$} & Pearson correlation & .767 & .246 & .436 & .887 & .878 & 1 & .879 & .736 & .824 & -.078 \\
\hline & 2-tailed significance & .000 & .012 & .000 & .000 & .000 & . & .000 & .000 & .000 & .428 \\
\hline & $\mathrm{N}$ & 105 & 105 & 105 & 105 & 105 & 105 & 105 & 105 & 105 & 105 \\
\hline \multirow[t]{3}{*}{$\mathrm{C} 4$} & Pearson correlation & .849 & .297 & .449 & .938 & .936 & .879 & 1 & .779 & .856 & .010 \\
\hline & 2-tailed significance & .000 & .002 & .000 & .000 & .000 & .000 & . & .000 & .000 & .917 \\
\hline & $\mathrm{N}$ & 105 & 105 & 105 & 105 & 105 & 105 & 105 & 105 & 105 & 105 \\
\hline \multirow[t]{3}{*}{ G } & Pearson correlation & .783 & .253 & .479 & .835 & .789 & .736 & .779 & 1 & .738 & -.009 \\
\hline & 2-tailed significance & .000 & .009 & .000 & .000 & .000 & .000 & .000 & . & .000 & .926 \\
\hline & $\mathrm{N}$ & 105 & 105 & 105 & 105 & 105 & 105 & 105 & 105 & 105 & 105 \\
\hline \multirow[t]{3}{*}{ S } & Pearson correlation & .812 & .157 & .357 & .861 & .862 & .824 & .856 & .738 & 1 & -.151 \\
\hline & 2-tailed significance & .000 & .111 & .000 & .000 & .000 & .000 & .000 & .000 & . & .125 \\
\hline & $\mathrm{N}$ & 105 & 105 & 105 & 105 & 105 & 105 & 105 & 105 & 105 & 105 \\
\hline \multirow[t]{3}{*}{ LGHBV } & Pearson correlation & -.081 & .076 & .028 & -.064 & -.052 & -.078 & .010 & -.009 & -.151 & 1 \\
\hline & 2-tailed significance & .411 & .441 & .773 & .517 & .596 & .428 & .917 & .926 & .125 & . \\
\hline & $\mathrm{N}$ & 105 & 105 & 105 & 105 & 105 & 105 & 105 & 105 & 105 & 105 \\
\hline
\end{tabular}

When stratified by fibrosis degree, liver expression of IL-17 was closely related with the degree of liver fibrosis of the patients. The higher the degree of liver fibrosis, the more strongly IL-17 was expressed in the liver, which was accompanied by a higher expression of the fibrotic markers, IV-C, LN, $\mathrm{HA}$, and PCIII. The P-values were $<0.05$ compared between each group from S0 to $\mathrm{S} 3$, and $<0.01$ compared between the S4 and S3 stage (Table IV).

There was also a close relationship between liver IL-17 expression and the activity level of liver inflammation. The expression of IL-17 increased as the activity level of liver inflammation got higher. From G1 to G3, the P-value was $<0.01$ for comparisons between each group, and $<0.05$ when comparing G4 and G3 (Table V).

Correlation analysis between intrahepatic expression of IL- 17 and liver transaminase levels, stage and grade of liver fibrosis and liver histopathology, and HBV DNA (Table VI). There was no correlation between intrahepatic IL-17 expression and ALT levels $(\mathrm{r}=0.225, \mathrm{P}>0.05)$, but a positive correlation existed between IL-17 expression and AST levels ( $r=0.367$, $\mathrm{P}<0.01)$.

Highly positive correlations were found between the IL-17 expression and all the markers of liver fibrosis (HA, LN, C3, C4), ( $r=0.832,0.818,0.767,0.849$, respectively; $\mathrm{P}<0.01$ for all). The stage and grade of liver fibrosis were also highly correlated with IL-17 expression in the liver $(\mathrm{r}=0.812, \mathrm{P}<0.01)$. When analyzing the correlation between IL-17 expression and the grade of liver inflammation a significant correlation was observed $(\mathrm{r}=0.783, \mathrm{P}<0.01)$. However, no significant correlation was found between IL-17 expression and the serum level of HBV DNA ( $\mathrm{r}=-0.081, \mathrm{P}>0.05)$.

\section{Discussion}

Our present study shows a significant increase in the expression of IL-17 in the serum, PBMCs, and liver tissues of patients with different chronic HVB-related hepatic diseases, such as 
chronic HBV hepatitis, chronic severe hepatitis B, CHB, LC, and hepatocellular carcinoma, especially in post-hepatitis B cirrhosis. Our results demonstrate the possible role of Th17 in the occurrence and development of chronic inflammation in patients with HBV infection. We also identified a significant correlation between intrahepatic IL-17 expression with the stage and grade of liver fibrosis and liver inflammation, which shows a possible role of Th17 in the development of liver fibrosis.

Imbalance of Th1/Th2 used to be considered the critical process that decides the clearance and the extent of HBV infection. The type of cytokines secreted by special $\mathrm{T}$ cells in the infection site may lead to different outcomes of HBV infection. Advantage of Th2 cells would be more likely to maintain a chronic carrier state, while advantage of Th1 cells appears to be associated with virus removal. When viral hepatitis occurs, clearance of the virus mainly relies on the CTL cells. In normal conditions, Th1 cells produce IFN- $\gamma$ and other cytokines to promote CTL cytotoxicity, and effectively remove the virus, which exhibits a transient acute inflammatory reaction. However, a significant decrease in the expression of IFN- $\gamma$ and an increase in that of IL-4 was found in the present study, which suggests a weakened Th1 response and an enhanced Th2 response. Beckebaum et al (9), found a dysfunction of dendritic cells (DCs) in maturation, self-differentiation, antigen presenting ability and the ability to induce maturation and differentiation of Th cells. This was presented as a deficiency of IL-12 secreted by DCs, which in turn resulted in a decreased ability of DCs to induce maturation and differentiation of Th1 cells. Meanwhile, direct destructive effects of the virus on the PBMCs also led to a reduced number and a decline in the function of Th1 cells (10).

Th17 comprise a newly discovered proinflammatory $\mathrm{T}$ cell subset. The Th17 response can be induced by activation of virus antigens. Th17 cells may regulate local antiviral immune responses by secreting inflammatory cytokines, which may in turn mediate tissue damage in humans. Mature Th17 cells have the ability to produce a series of inflammatory cytokines such as IL-17A (IL-17), IL-17F, and IL-6. IL-17 has strong immune pathogenicity, which can promote $\mathrm{T}$ cell activation and can stimulate fibroblasts, endothelial cells, macrophages, and epithelial cells to produce a variety of inflammatory factors (including IL-1, IL-6, TNF- $\alpha$, NOS-2, metalloproteinases, and chemical activin), which lead to inflammation $(11,12)$. IL-17 was recently found to be extensively involved in the pathogenesis of chronic liver disease and antiviral immunity (4). A recent study has indicated that IL-17 up-regulated anti-apoptotic molecules and thus induced persistent infection by enhancing the survival of virus infected cells, suggesting a novel pathogenic role of Th17 cells during persistent viral infection (13). These studies suggest that IL-17 may contribute to the immunopathogenesis induced by persistent viral infection; however, the role of IL-17 in liver fibrosis and cirrhosis after HBV infection remains unknown.

Hepatic fibrosis is closely related to the complicated changes in cell-cytokine-ECM $(14,15)$, which lead to an imbalance between the synthesis and degradation of the ECM. An important role of non-HBV specific inflammation in the progress of chronic HBV infection has been suggested
(16-18). Recent studies have also found more important associations between the immune system and liver fibrosis and tissue repair and recovery that are vital for the maintenance of tissue homeostasis. The inflammation of the liver induces the active mesenchymal cells to express a large number of TGF- $\beta$, which was an important pro-fibrosis factor, and was demonstrated to play an important role in the differentiation and development of Th17. The combined effects of TGF- $\beta$ and IL- 6 could initiate the rapid differentiation of $\mathrm{CD} 4^{+}$naive cells to Th17.

In our study, we identified significant increases in the serum levels and intrahepatic expression of IL-17 in patients of hepatic cirrhosis. As the classification of hepatic fibrosis got higher, IL-17 levels increased gradually. In patients with liver cirrhosis however, there was no significant difference in the score of staining between active and inactive hepatic cirrhosis, yet the staining intensity significantly deepened in patients with active compared with quiescent liver cirrhosis. At the same time, our immunohistochemistry results showed that IL-17 is mainly localized in the fibrosis area. All the above results indicated an important role of IL-17 in the formation and development of liver fibrosis. As mentioned above, there is a close biological link between IL-17 and these hepatic fibrosis-related cytokines such as TGF- $\beta$, TNF- $\alpha$, IL- 6 and IL-1. Previous studies have indicated the key role of TGF- $\beta 1$ in the development of liver fibrosis $(19,20)$, which was found to be significantly increased in patients with hepatic fibrosis and cirrhosis. Meanwhile, TGF- $\beta 1$ has been shown to play an important role in the differentiation and development of Th17 $(21,22)$, and together with IL-6 can initiate the rapid differentiation of naive $\mathrm{CD} 4^{+} \mathrm{T}$ cells to Th17 (23). Notably, a recent study indicated that hepatic stellate cells (HSCs) can express the IL-17 receptor (IL-17R). Following IL-17 stimulation in vitro they can secret IL- 8 and GRO- $\alpha$ and subsequently recruit neutrophils into the livers of patients with alcoholic liver disease (5). As activation of HSCs is the key process responsible for the fibrosis, it is reasonable to believe that IL-17 promotes fibrosis through the activation of HSC, and it may also be a common product of a variety of factors causing fibrosis.

Our study found a correlation between the serum concentration of IL-17 and that of some indicators of liver function, especially of ALT, which showed a negative correlation with IL-17. This is probably because IL-17 is closely related to chronic inflammation and is an important proinflammatory cytokine that activates a variety of immune cells to release inflammatory mediators, leading to repeated inflammation of the liver and damage of liver function.

We also found extremely elevated IFN- $\gamma$ expression in several cases of patients with acute hepatitis B, whose IL-17 levels were significantly lower than in healthy people (data not shown). Therefore, chronic inflammation would not account for the occurrence; the low level of IL-17 may result from a strong suppression by IFN- $\gamma$. Furthermore, in our study, there was no significant difference in IFN- $\gamma$ expression in cases of cirrhosis, chronic hepatitis and in the control group, but the IFN/IL-4 ratio in cirrhosis group was significantly higher than in the chronic hepatitis group. We speculated that was due to the increased T cell-mediated specific immunity in patients with cirrhosis compared with CHB; it may also be 
due to the anti-fibrosis effect of IFN- $\gamma$ consistent with some other research $(24,25)$.

In summary, our study confirms the enhanced expression of IL-17 in HBV-associated diseases, such as CHB, hepatic carcinoma, severe hepatitis, and especially post-hepatitis B liver cirrhosis, in which the intrahepatic expression of IL-17 is significantly higher than in CHB cases. Furthermore, as the degree of liver fibrosis gets higher, IL-17 expression increases. Meanwhile, there is a significant positive correlation between IL-17 expression and the inflammatory activity levels of chronic hepatitis B and the grade of liver fibrosis. All these results indicate the important role of IL-17-producing cells in the development of chronic HBV infection and the formation of liver fibrosis, which suggests that effective blocking of the expression of IL-17 is important in controlling the inflammatory response in chronic hepatitis $\mathrm{B}$ and liver fibrosis in addition to the occurrence as well as the development of cirrhosis.

\section{Acknowledgements}

This study was performed in the Division of Gastroenterology Laboratory of the Union Hospital, Wuhan, China. We thank all colleagues who helped us and especially Jinping Zhang for advice on manuscript preparation.

\section{References}

1. Infante-Duarte C, Horton HF, Byrne MC and Kamradt T: Microbial lipopeptides induce the production of IL-17 in Th cells. J Immunol 165: 6107-6115, 2000.

2. Langrish CL, Chen Y, Blumenschein WM, et al: IL-23 drives a pathogenic $\mathrm{T}$ cell population that induces autoimmune inflammation. J Exp Med 201: 233-240, 2005.

3. Park H, Li Z, Yang XO, et al: A distinct lineage of CD4 T cells regulates tissue inflammation by producing interleukin 17 . Nat Immunol 6: 1133-1141, 2005.

4. Lafdil F, Miller AM, Ki SH and Gao B: Th17 cells and their associated cytokines in liver diseases. Cell Mol Immunol 7: 250-254, 2010

5. Lemmers A, Moreno C, Gustot T, et al: The interleukin-17 pathway is involved in human alcoholic liver disease. Hepatology 49: 646-657, 2009

6. Zhang JY, Zhang Z, Lin F, et al: Interleukin-17-producing CD4(+) T cells increase with severity of liver damage in patients with chronic hepatitis B. Hepatology 51: 81-91, 2010.

7. Holt AP, Salmon M, Buckley CD and Adams DH: Immune interactions in hepatic fibrosis. Clin Liver Dis 12: 861-882, 2008.

8. Lok AS and McMahon BJ: Chronic hepatitis B. Hepatology 45: 507-539, 2007.
9. Beckebaum S, Cicinnati VR, Zhang X, et al: Hepatitis B virusinduced defect of monocyte-derived dendritic cells leads to impaired $\mathrm{T}$ helper type 1 response in vitro: mechanisms for viral immune escape. Immunology 109: 487-495, 2003.

10. Freeman AJ, Marinos G, Ffrench RA and Lloyd AR: Immunopathogenesis of hepatitis $\mathrm{C}$ virus infection. Immunol Cell Biol 79: 515-536, 2001.

11. Kolls JK and Linden A: Interleukin-17 family members and inflammation. Immunity 21: 467-476, 2004.

12. Nakae S, Saijo S, Horai R, Sudo K, Mori S and Iwakura Y: IL-17 production from activated $T$ cells is required for the spontaneous development of destructive arthritis in mice deficient in IL-1 receptor antagonist. Proc Natl Acad Sci USA 100: 5986-5990, 2003.

13. Hou W, Kang HS and Kim BS: Th17 cells enhance viral persistence and inhibit $\mathrm{T}$ cell cytotoxicity in a model of chronic virus infection. J Exp Med 206: 313-328, 2009.

14. Friedman SL: Seminars in medicine of the Beth Israel Hospital, Boston. The cellular basis of hepatic fibrosis. Mechanisms and treatment strategies. N Engl J Med 328: 1828-1835, 1993.

15. Olaso E and Friedman SL: Molecular regulation of hepatic fibrogenesis. J Hepatol 29: 836-847, 1998.

16. Szabo G, Mandrekar P and Dolganiuc A: Innate immune response and hepatic inflammation. Semin Liver Dis 27: 339-350, 2007.

17. Bertoletti A and Naoumov NV: Translation of immunological knowledge into better treatments of chronic hepatitis B. J Hepatol 39: 115-124, 2003.

18. Guidotti LG and Chisari FV: Noncytolytic control of viral infections by the innate and adaptive immune response. Annu Rev Immunol 19: 65-91, 2001.

19. Gressner AM and Weiskirchen R: Modern pathogenetic concepts of liver fibrosis suggest stellate cells and TGF-beta as major players and therapeutic targets. J Cell Mol Med 10: 76-99, 2006.

20. Kopp J, Seyhan H, Muller B, et al: N-acetyl-L-cysteine abrogates fibrogenic properties of fibroblasts isolated from Dupuytren's disease by blunting TGF-beta signalling. J Cell Mol Med 10: $157-165,2006$

21. Veldhoen M and Stockinger B: TGFbeta1, a 'Jack of all trades': the link with pro-inflammatory IL-17-producing T cells. Trends Immunol 27: 358-361, 2006.

22. Qin H, Wang L, Feng T, et al: TGF-beta promotes Th17 cell development through inhibition of SOCS3. J Immunol 183: 97-105, 2009.

23. Bettelli E, Carrier Y, Gao W, et al: Reciprocal developmental pathways for the generation of pathogenic effector TH17 and regulatory T cells. Nature 441: 235-238, 2006.

24. Henri S, Chevillard C, Mergani A, et al: Cytokine regulation of periportal fibrosis in humans infected with Schistosoma mansoni: IFN-gamma is associated with protection against fibrosis and TNF-alpha with aggravation of disease. J Immunol 169: 929-936, 2002.

25. Booth M, Mwatha JK, Joseph S, et al: Periportal fibrosis in human Schistosoma mansoni infection is associated with low IL-10, low IFN-gamma, high TNF-alpha, or low RANTES, depending on age and gender. J Immunol 172: 1295-1303, 2004. 